\title{
Anionic Surfactant Templated Titanium Oxide Mesophase: Synthesis, Characterization and Mechanism of Formation
}

\section{Vittorio Luca et al.}

\section{Supporting Information Section}

\section{$\mathrm{Ti}_{8}$ Structure}

The $\mathrm{Ti}_{8}$ oxo-alkoxy cluster compound referred to in the present submission has the formula $\mathrm{Ti}_{8}\left(\mu_{4}-\mathrm{O}\right)_{2}\left(\mu_{2}-\mathrm{O}\right)_{3}\left(\mathrm{SO}_{4}\right)_{2}\left(\mu_{2^{-}}\right.$ $\mathrm{OEt})_{10}\left(\mu_{1}-\mathrm{OEt}\right)_{8}$ and an associated manuscript describing the preparation and structure has been submitted to Acta Cryst. C.

An ORTEP view of the cluster is shown below in Figure 1 and a

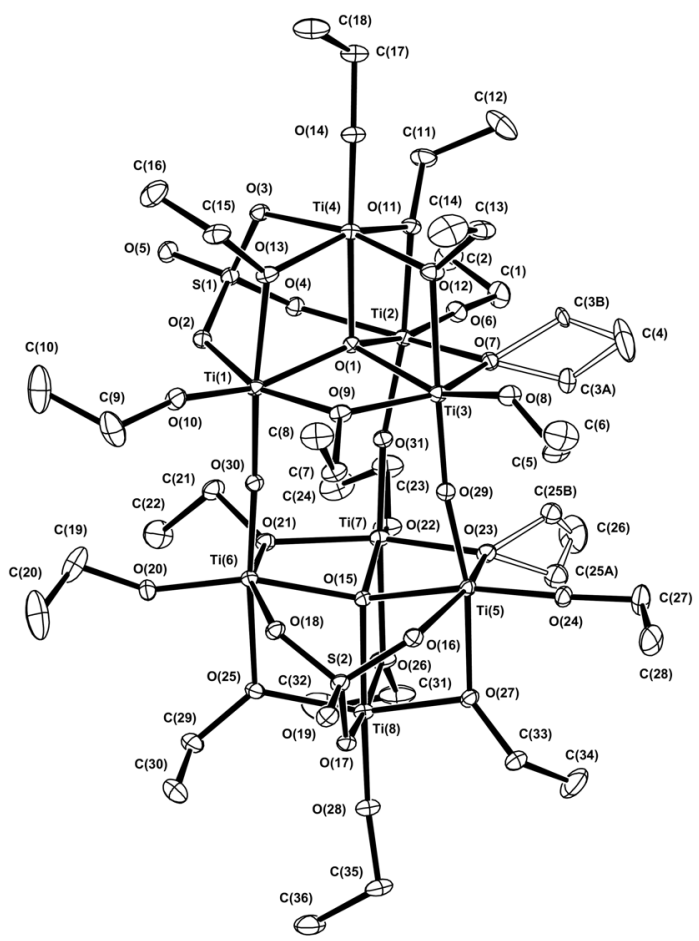

Figure. 1 ORTEP ${ }^{21}$ depiction of of the $\mathbf{T i}_{8}$ cluster, with displacement ellipsoids shown at the $20 \%$ level.

summary of crystallographic parameters appears in Tables I-III.

The FTIR spectrum of the $\mathrm{Ti}_{8}$ cluster in the $1600-500 \mathrm{~cm}^{-1}$ region is shown in Figure 2, along with those of sodium dodecyl sulphate (SDS), the titanium(III) dodecyl sulfate precursor, and tetraethylorthotitanate, $\mathrm{Ti}(\mathrm{OEt})_{4}$. Positions and assignments for the major bands or the $\mathbf{T i}_{\mathbf{8}}$-cluster spectrum are listed in Table IV. The spectrum is dominated by vibrations of the terminallybonded and bridging ethoxide ligands, as expected from the cluster composition, and these are assigned by analogy with

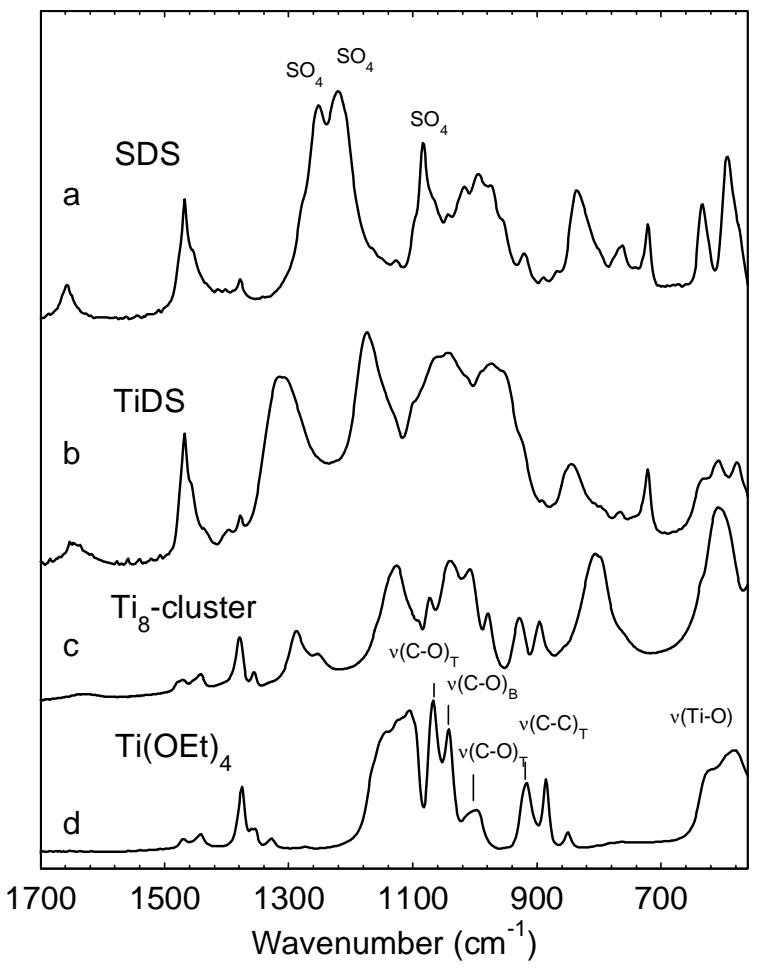

Figure. 2. FTIR spectra at $298 \mathrm{~K}$ of (a) sodium dodecyl sulfate, (b) Ti-dodecyl sulfate precipitate, (c) $\mathbf{T i}_{\mathbf{8}}$-cluster and (d) $\operatorname{Ti}(\mathrm{OEt})_{4}$.

assignments for these species in tetraethylorthotitanate (Finnie et $a l ., 2000)$.

Relative to the ethoxide ligands, the two sulfato anions per cluster are expected to contribute only weakly to the spectrum. However, the strongest sulfate bands, involving S-O antisymmetric stretching vibrations, are clearly observed at 1288 and $1254 \mathrm{~cm}^{-1}$. These modes occur at 1252 and $1220 \mathrm{~cm}^{-1}$ in the spectrum of the sodium lauryl sulfate, with a corresponding symmetric stretch at $1083 \mathrm{~cm}^{-1}$; the similarity to alkyl sulfonate spectra reflects the $\mathrm{R}-\mathrm{O}-\mathrm{SO}_{3}{ }^{-}$bonding geometry in the sulphate (Hummel, 1996).

Finally, the strong $\mathbf{T i}_{\mathbf{8}}$ bands at 806 and $795 \mathrm{~cm}^{-1}$ are too intense to be due to sulfate, and are not assignable to ethoxide. Hence we assign these bands to Ti-O-Ti stretching of $\mu_{2}-\mathrm{O}$, in agreement with the tentative assignment for $\mu_{2}-\mathrm{O}$ in $\mathrm{Ti}_{6} \mathrm{O}_{4}(\mathrm{OEt})_{8}(\mathrm{OMc})_{8}\left(\mathrm{OMc}=\mathrm{OC}(\mathrm{O}) \mathrm{C}\left(\mathrm{CH}_{3}\right)=\mathrm{CH}_{2}\right) .{ }^{24}$ We do not observe the other band assigned to $\mu_{2}-\mathrm{O}$, at $687 \mathrm{~cm}^{-1}$; however, this is likely to be strongly mixed with the Ti-O stretch of the ethoxide ligands $\sim 608 \mathrm{~cm}^{-1}$. 
The chemistry of the poorly crystalline titanium dodecylsulfate (TDS) precursor from which $\mathbf{T i}_{\mathbf{8}}$ is synthesized has never been described. The powder XRD pattern of TDS (not shown) has reflections at 33.7, 16.6 and $11.0 \AA$ indicating that this compound has a lamellar structure similar to that of SDS. The FTIR spectrum of TDS differs significantly from that of SDS. Importantly, there is a dramatic change in the sulfate antisymmetric stretching bands on formation of TDS, although the $v_{\mathrm{s}}(\mathrm{C}-\mathrm{O}-\mathrm{S})$ is retained at $843 \mathrm{~cm}^{-1}\left(836 \mathrm{~cm}^{-1}\right.$ in SDS $)$, indicating that the $\mathrm{C}-\mathrm{O}-\mathrm{SO}_{3}$ bond has for the most part remained intact. Intense bands at 1314 and 1305 (unresolved) and 1174 $\mathrm{cm}^{-1}$, suggest that sulfate geometry is significantly altered from that in SDS. The 1314, 1305 and $1174 \mathrm{~cm}^{-1}$ band positions are similar to characteristic $-\mathrm{SO}_{2}$ - stretching frequencies (Lin-Vein et al., 1991). For example, in sulfones, $\mathrm{R}-\mathrm{SO}_{2}-\mathrm{R}$, there are strong bands at $1330-1295$ and $1152-1125 \mathrm{~cm}^{-1}$, and in sulfates, RO-SO ${ }_{2}-\mathrm{OR}$, at 1388-1372 and 1196-1188 $\mathrm{cm}^{-1}$, corresponding to $\mathrm{v}_{\mathrm{as}}\left(\mathrm{SO}_{2}\right)$ and $\mathrm{v}_{\mathrm{s}}\left(\mathrm{SO}_{2}\right)$ respectively. Thus, a structure (R-O$\left.\mathrm{S}(=\mathrm{O})_{2}-\mathrm{O}^{-}\right)_{3} \mathrm{Ti}$ is predicted for TDS.

The FTIR spectrum of TDS dissolved in ethanol was measured in order to look for evidence of coordination of ethoxide in solution. While most ethoxide IR vibrations are overlapped by those of ethanol, there are two regions where bands distinct to ethoxide occur. The first is the region $1100-$ $1160 \mathrm{~cm}^{-1}$, corresponding to a methyl rocking mode, and the second is the region $900-940 \mathrm{~cm}^{-1}$, which is the expected range of the C-C stretching mode of terminally-bonded ethoxide. Comparison of the spectra of TDS dissolved in ethanol and tetrachloride (which is not expected to coordinate) showed that

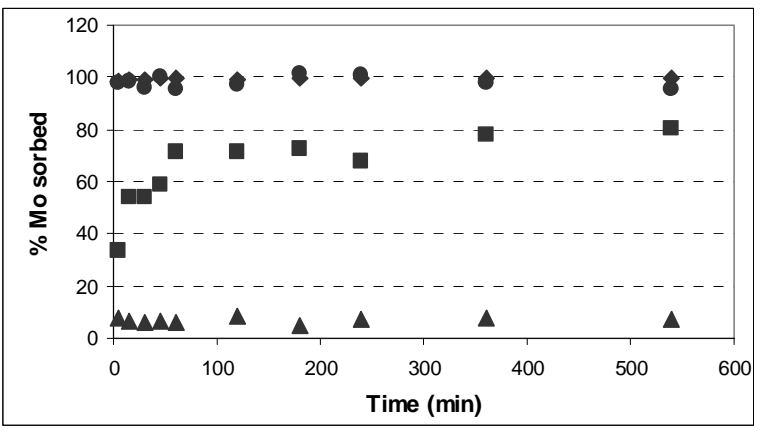

Figure 3. Mo adsorption at $\mathrm{pH}=1$ and 13 on TOM- 3 materials at $\mathrm{pH}=1$ $(\bullet)$ and $\mathrm{pH}=13(\boldsymbol{\bullet})$ in comparison with $\gamma$-alumina at $\mathrm{pH}=1(\bullet)$ and $\mathrm{pH}=$ $13(\boldsymbol{\Delta})$.

new bands appeared in the ethanol-solution spectrum at 1149 , 930 and $915 \mathrm{~cm}^{-1}$, which is consistent with the formation of Tiethoxide bonds.

\section{Ion Exchange Properties}

TOM- $x$ samples can be readily exchanged with oxo anions such as $\mathrm{H}_{x} \mathrm{M}^{\mathrm{n}} \mathrm{O}_{4}^{8-\mathrm{n}-x}$ (where $\mathrm{M}=\mathrm{Cr}^{6+}, \mathrm{V}^{5+}, \mathrm{W}^{6+}, \mathrm{Mo}^{6+}$ ) and other anionic species by simply treating a suspension of $0.5 \mathrm{~g}$ TOM-3 in $20 \mathrm{~mL}$ of mill-Q water with a calculated amount of 10-40 $\mathrm{mg} / \mathrm{L}$ solution of the anion at the $\mathrm{pH}$ of interest. For conventional $\mathrm{TiO}_{2}$ the $\mathrm{pH}$ at $\mathrm{PZC}$ is about 6.0-6.6 and so relatively little adsorption is expected at high $\mathrm{pH}$ values. On the other hand TOM materials can adsorb these oxo anions strongly from quite alkaline $\mathrm{pH}$ solutions. In the case of molybdate exchange, EDS analyses of powder samples and chemical analyses show that complete exchange of sulphate occurs.
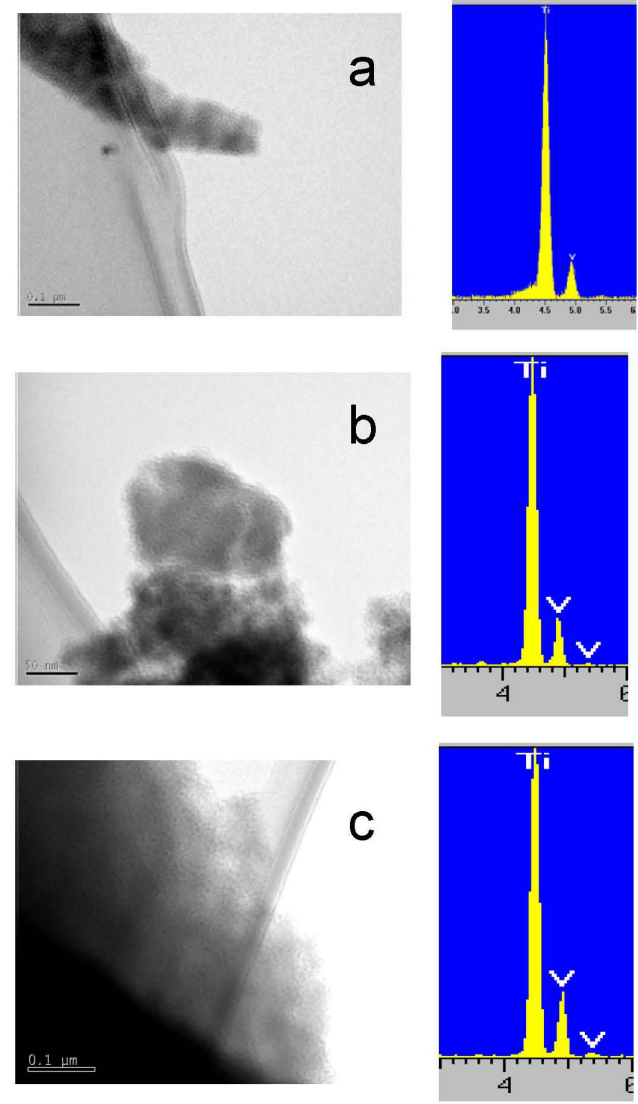

Figure 4 TEM images and EDS of progressively V-exchanged TOM-3. Exchange performed at $\mathrm{pH}=12$ using $40 \mathrm{mM} \mathrm{NH}_{4} \mathrm{VO}_{3}$ solution which was added to the TOM-3 suspension. Level of exchange $\}$ d calculated according to the theoretical cation exchange capacity based mol \% S. (a) 0.25 (b) 0.50 and (c) 1.0 times the AEC.

Figure 3 demonstrates the uptake of molybdate from 10 $\mathrm{mg} / \mathrm{L}$ solutions at two distinct $\mathrm{pH}$ values compared with gamma alumina. Thus molybdate can be completely extracted using 1-2 $\mathrm{mol} / \mathrm{L} \mathrm{NaOH}$ solutions.

TEM images and corresponding EDS analyses of Vexchanged TOM-3 samples are shown in Figure 4. A progressive increase in the intensity of the $\mathrm{V}$ X-ray line relative to that of $\mathrm{Ti}$ is observed on increasing the $\mathrm{V}$ concentration in the solutions used for ion exchange. The anion ion-exchange capacity (AEC) can be taken as the $\mathrm{mmol} / \mathrm{g}$ of sulphate in the solid. The ${ }^{51} \mathrm{~V}$ MAS NMR spectra of samples exchanged to $0.25 \mathrm{x}$ and 1.0x the AEC also verify the increase in $\mathrm{V}$ content on increasing the $\mathrm{V}$ solution concentration (Figure 5). The spectra show that at least three $\mathrm{V}$ species are present irrespective of loading. Moreover, the spectra show only a very weak spinning side band manifold indicating a relatively small chemical shift anisotropy and quadrupole moment as might be expected for isolated tetrahedral vanadate species.

TOM-3 samples exchanged with Mo in similar fashion to the V-TOM-3 samples were examined by Mo K-edge EXAFS recorded at $10 \mathrm{~K}$. In the case of both the $0.25 \mathrm{x}$ and $1.0 \mathrm{x}$ AEC samples, only a very weak second shell FT peak is observed after drying at $70{ }^{\circ} \mathrm{C}$ (Figure 6a,c), This indicates that molybdate oxo species adsorbed on the TOM surface during ion exchange are in a highly dispersed state. However, calcination at $400{ }^{\circ} \mathrm{C}$ 


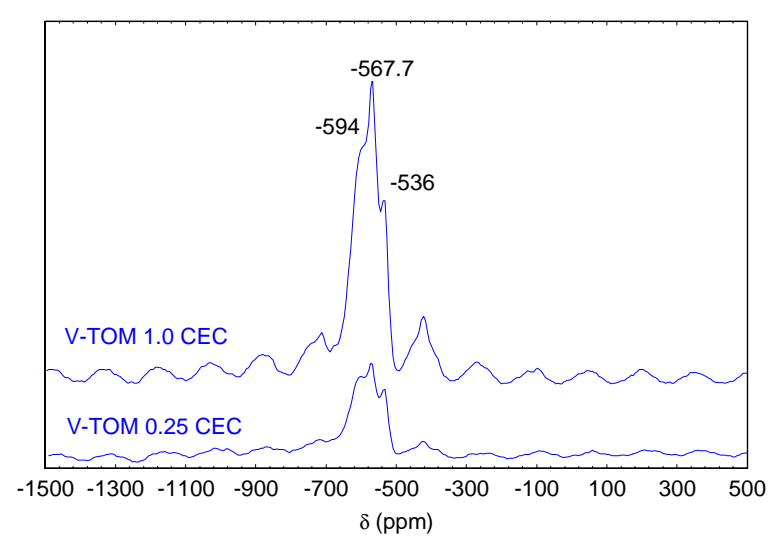

Figure 5. ${ }^{51} \mathrm{~V}$ MAS NMR spectra of V-TOM-3 samples from Figure 4 after exchange at the level of 0.25 and 1.0 times the theoretical CEC. Spectra were recorded identically and so relative intensities reflect the $\mathrm{V}$ concentration.
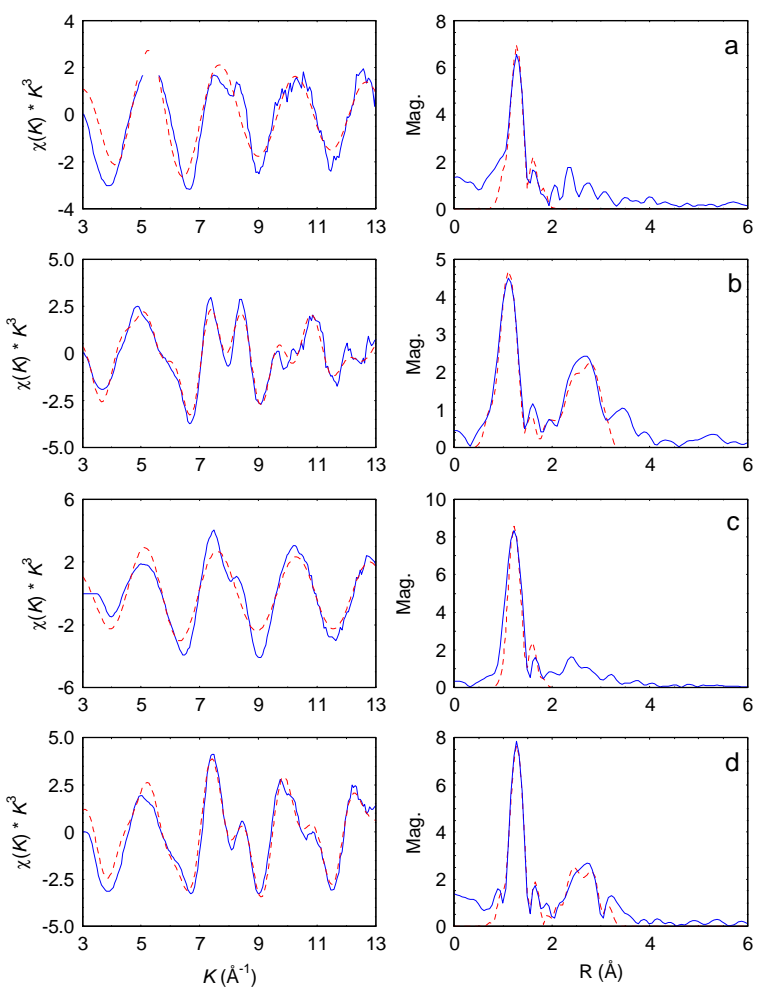

Figure 6. Mo $K$-edge EXAFS spectra of Mo-exchanged TOM-3 materials. (a) 0.25 after drying at $70{ }^{\circ} \mathrm{C}$ and (b) after heating $400{ }^{\circ} \mathrm{C}$ in air for $2 \mathrm{~h}$. (c) 1.0 after drying at $70{ }^{\circ} \mathrm{C}$ and (d) after heating $400{ }^{\circ} \mathrm{C}$ in air for $2 \mathrm{~h}$.

(Figure $6 \mathrm{~b}, \mathrm{~d}$ ) induces a degree of aggregation as evidenced by an increase in the intensity of this second shell FT peak for both levels of exchange. Apart from an increase in Mo-O-Mo bonding there may be some increasing contribution to this second shell peak due to Mo-O-Ti bonding on break down of the porous structure.

\section{Optical Spectroscopy and Electronic Properties}

A measure of the direct optical band gap of the TOM-3 material for comparison with other nanocrystalline titania materials can be obtained in the usual way by measuring the diffuse reflectance UV-Vis spectra of the samples and plotting as $(\mathrm{F}(\mathrm{R})$ $\mathrm{x} h v)^{2}$ versus $h v$ where $\mathrm{F}(\mathrm{R})$ is the Kebulka-Munk function. Fitting the linear portion of the absorption onset and extrapolating to zero ordinate then gives the gap energy (Figure 7). It is apparent that the optical band gap of the amorphous

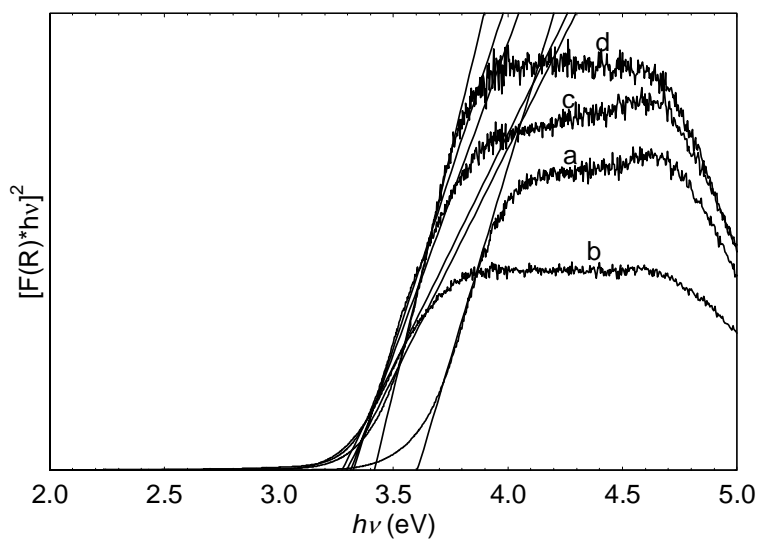

Figure 7. Diffuse reflectance UV-visible spectra of (a) amorphous titania $\mathrm{D}<20 \AA, \mathrm{E}_{\mathrm{g}}=3.60 \mathrm{eV}$, (b) nanocrystalline titania with average particle diameter $\mathrm{D}=20 \AA, \mathrm{E}_{\mathrm{g}}=3.28 \mathrm{eV}$, (c) nanocrystalline titania $\mathrm{D}=$ $130 \AA, \mathrm{E}_{\mathrm{g}}=3.32 \mathrm{eV}$, (d) TOM-3 sample, $\mathrm{E}_{\mathrm{g}}=3.41 \mathrm{eV}$. The linear portion of the absorption onset has been fitted to a straight line which is extrapolated to zero to determine the direct gap. Similar results are obtained if an indirect band gap is assumed.

titania is the largest at $3.60 \mathrm{eV}$ and blue shifted relative to nano particulate anatase materials as observed previously. Both nanocrystalline anatase samples have approximately the same gap energy while the TOM-3 material fits in between these extremes with a gap energy of $3.42 \mathrm{eV}$. This seems reasonable since dimensional confinement might be expected in such a mesostructured system.

\section{Thermal Analysis}

The TGA-DTA traces for a TOM-3 is given in Figure 8. The sample loses weight in several discrete steps. An initial 30\% weight loss occurs up to about $200{ }^{\circ} \mathrm{C}$. An abrupt kink occurs in the weight loss curve at about $200{ }^{\circ} \mathrm{C}$ and a strong exothermic peak is observed. Between 200 and $400{ }^{\circ} \mathrm{C}$ a $10 \%$ weight loss occurs. The kink and the exotherm are presumably due to combustion of the surfactant and is often observed when heating in air (Luca et al., 1997). In cetyltrimethyl ammonium surfactant based titania mesophase materials a strong exotherm due to surfactant elimination is also observed just under $300{ }^{\circ} \mathrm{C}$. The bulk of the organic material therefore appears to be removed between about 300 and $400{ }^{\circ} \mathrm{C}$. At about $600{ }^{\circ} \mathrm{C}$ a rapid weight loss of an additional $10 \%$ occurs and another exothermic peak is observed. The weight loss and exotherm are due either to dehydroxylation of the titanium oxide that forms on the elimination of sulfur. In cetyltrimethyl ammonium surfactant based titania mesophase materials a strong exotherm due to surfactant elimination is also observed just under $300{ }^{\circ} \mathrm{C}$ (Soler- 


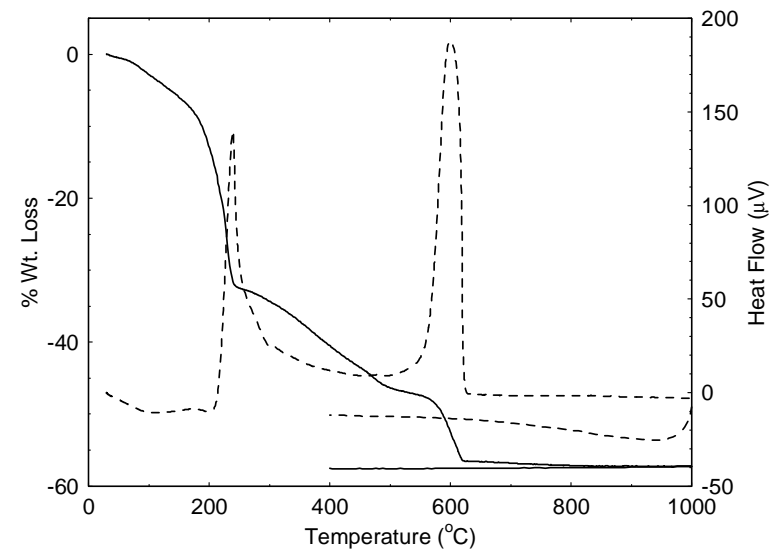

Figure 8. Thermal analysis trace of TOM-3 material recorded in flowing air.

Illia et al., 2002). The bulk of the organic material therefore appears to be removed between about 300 and $400{ }^{\circ} \mathrm{C}$. At about $600{ }^{\circ} \mathrm{C}$ a rapid weight loss of an additional $10 \%$ occurs and another exothermic peak is observed. This weight loss and exotherm are due either to dehydroxylation of the titanium oxide that forms or the elimination of sulfur.

\section{Porosity}

Porosity is made available in the TOM materials by extraction of the sulphate surfactant using an ion-exchange process. The porosity of the V-exchanged materials described previously was measured after calcination at $300{ }^{\circ} \mathrm{C}$. The BET surface areas of the samples exchanged with an increasing concentration of vanadium is plotted against the fraction of the theoretical anion exchange capacity, f, in Figure 9. It can be seen that the surface area is maximized for $\mathrm{f}=0.5$ and then progressively decreases. Presumably this indicates that the pores are being filled with vanadate.

\section{References}

Finnie, K.S., Luca, V. Moran, P. D., Bartlett, J. R.and Woolfrey, J. L. J. Mater. Chem. 2000, 10, 409-418.

Hummel, D. O. Analysis of Surfactants,(Hanser Publishers, Munich, 1996), p. 11.

Lin-Vein, D. et al., The Handbook of Infrared and Raman Characteristic Frequencies of Organic Molecules,(Academic Press, San Diego, 1991), p. 245.

Luca, V.; MacLachlan, D. J.; Morgan, K. Chem. Mater. 1997, 9, 2720.

Soler-Illia, G. J.; Louis, A.; Sanchez, C. Chem. Mater. 2002, 14, 750 .

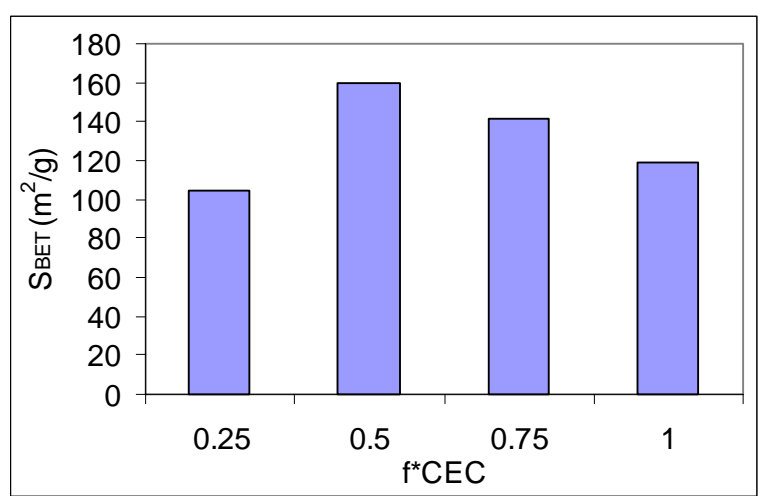

Figure 9. BET surface area as a function of the level exchange of TOM sample expressed as the fraction of theoretical capacisty based on the surfactant content. Samples are those corresponding to the data in Figures 4 and 5 and were calcined at $300{ }^{\circ} \mathrm{C}$ prior to measurement. 


\section{$\mathbf{T i}_{8}$ Cluster Crystallography}

Table I. Crystallographic Data for $\mathrm{Ti}_{8}\left(\mu_{4}-\mathrm{O}\right)_{2}\left(\mu_{2}-\mathrm{O}\right)_{3}\left(\mathrm{SO}_{4}\right)_{2}\left(\mu_{2^{-}}\right.$ $\mathrm{OEt})_{10}\left(\mu_{1} \mathrm{OEt}\right)_{8}$.

\begin{tabular}{|c|c|}
\hline Formula of the Refinement Model & $\mathrm{C}_{40} \mathrm{H}_{102} \mathrm{O}_{33} \mathrm{~S}_{2} \mathrm{Ti}_{8}$ \\
\hline Model Molecular Weight & 1558.54 \\
\hline Crystal System & triclinic \\
\hline Space Group & $P \overline{1}(\# 2)$ \\
\hline$a$ & $12.605(2) \AA$ \\
\hline$b$ & $21.903(4) \AA$ \\
\hline$c$ & $12.588(2) \AA$ \\
\hline$\alpha$ & $92.235(3)^{\circ}$ \\
\hline$\beta$ & $95.794(1)^{\circ}$ \\
\hline$\gamma$ & $88.167(3)^{\circ}$ \\
\hline V & $3461.9(10) \AA^{3}$ \\
\hline $\mathrm{D}_{\mathrm{c}}$ & $1.495 \mathrm{~g} \mathrm{~cm}^{-3}$ \\
\hline$Z$ & 2 \\
\hline Crystal Size & $0.340 \times 0.330 \times 0.188 \mathrm{~mm}$ \\
\hline Crystal Colour & colourless \\
\hline Crystal Habit & prism \\
\hline$\lambda\left(\mathrm{MoK}_{\alpha}\right)$ & $0.71069 \AA$ \\
\hline$\lambda\left(\right.$ Mo K$\left._{\alpha}\right)$ & $1.013 \mathrm{~cm}^{-1}$ \\
\hline $\mathrm{T}(\text { Gaussian })_{\min , \max }$ & $0.666,0.853$ \\
\hline $2 \theta_{\max }$ & $56.60^{\circ}$ \\
\hline hkl range & $-1616,-2828,-1616$ \\
\hline $\mathrm{N}$ & 29710 \\
\hline $\mathrm{N}_{\text {ind }}$ & $15167\left(R_{\text {merge }} 0.0334\right)$ \\
\hline $\mathrm{N}_{\text {obs }}$ & $12556(\mathrm{I}>2 \sigma(\mathrm{I}))$ \\
\hline $\mathrm{N}_{\mathrm{var}}$ & 786 \\
\hline Residuals $^{*} \mathrm{R} 1(\mathrm{~F}), \mathrm{wR} 2\left(\mathrm{~F}^{2}\right)$ & $0.0507,0.1368$ \\
\hline GoF(all) & 1.283 \\
\hline Residual Extrema & $-0.633,0.910 \mathrm{e}^{-} \AA^{-3}$ \\
\hline $\begin{array}{l}R 1=\Sigma|| F_{\mathrm{o}}|-| F_{\mathrm{c}}|| / \Sigma\left|F_{\mathrm{o}}\right| \text { for } F_{\mathrm{o}}> \\
\left.\left.\left.F_{\mathrm{c}}^{2}\right)^{2} / \Sigma\left(\mathrm{w} F_{\mathrm{c}}\right)^{2}\right)^{2}\right)^{1 / 2} \text { all reflections }\end{array}$ & $2 \sigma\left(F_{\mathrm{o}}\right) ; w R 2=\left(\Sigma \mathrm{w}\left(F_{o}^{2}-\right.\right.$ \\
\hline
\end{tabular}

Table II. Selected bond lengths $(\AA)$ for $\mathrm{Ti}_{8}\left(\mu_{4}-\mathrm{O}\right)_{2}\left(\mu_{2-}\right.$ $\mathrm{O})_{3}\left(\mathrm{SO}_{4}\right)_{2}\left(\mu_{2}-\mathrm{OEt}\right)_{10}\left(\mu_{1} \mathrm{OEt}\right)_{8}$.

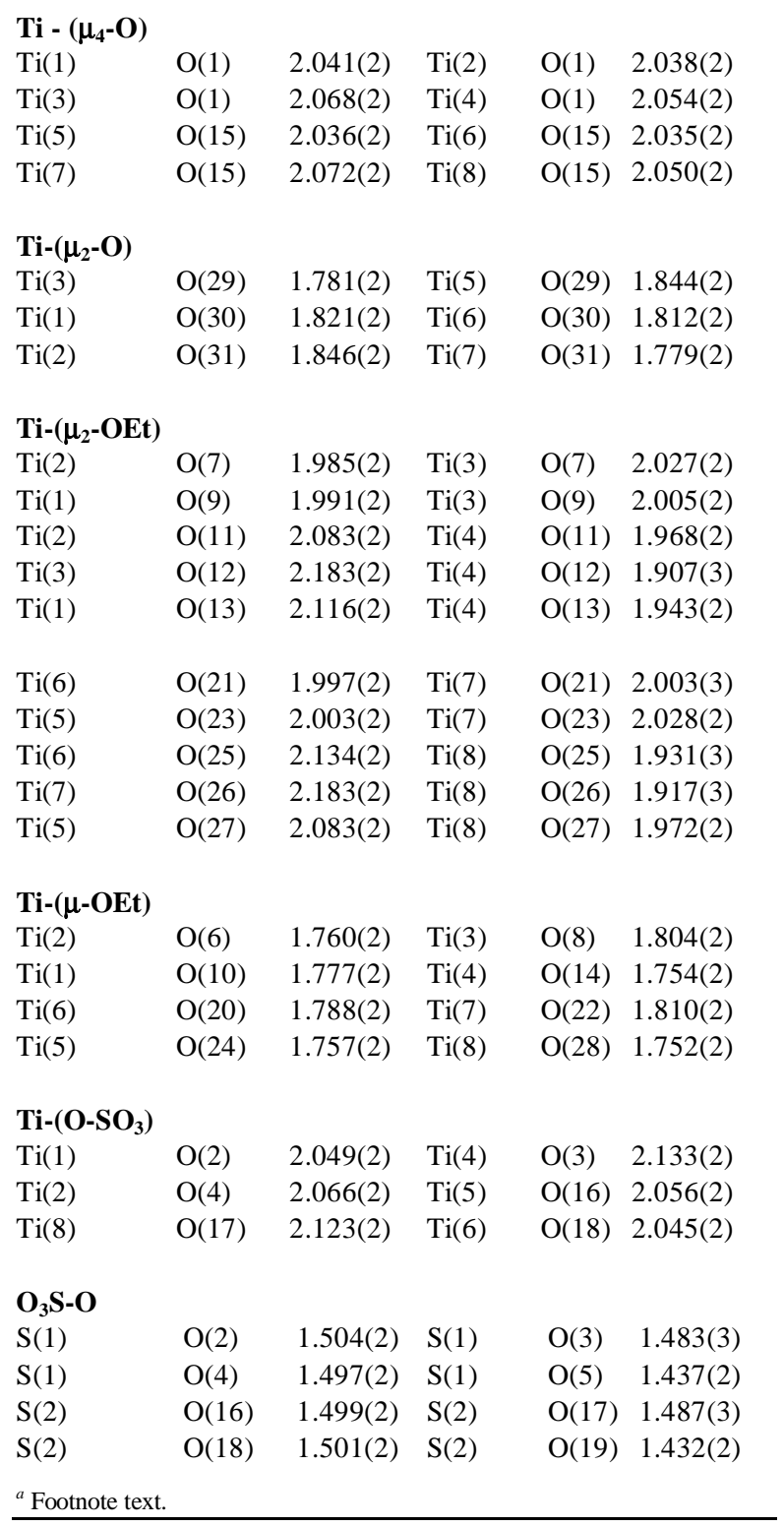


Table III. Selected Bond Angles $(\AA)$ of $\mathrm{Ti}_{8}\left(\mu_{4}-\mathrm{O}\right)_{2}\left(\mu_{2^{-}}\right.$ $\mathrm{O})_{3}\left(\mathrm{SO}_{4}\right)_{2}\left(\mu_{2}-\mathrm{OEt}\right)_{10}\left(\mu_{1} \mathrm{OEt}\right)_{8}$

\begin{tabular}{|c|c|c|c|}
\hline \multicolumn{4}{|c|}{$\mathbf{T i}-\left(\mu_{4}-\mathrm{O}\right)-\mathbf{T i}$} \\
\hline $\operatorname{Ti}(1)$ & $\mathrm{O}(1)$ & $\operatorname{Ti}(2)$ & $141.17(11)$ \\
\hline $\operatorname{Ti}(1)$ & $\mathrm{O}(1)$ & $\operatorname{Ti}(3)$ & $101.43(9)$ \\
\hline $\operatorname{Ti}(1)$ & $\mathrm{O}(1)$ & $\operatorname{Ti}(4)$ & $102.59(10)$ \\
\hline $\operatorname{Ti}(2)$ & $\mathrm{O}(1)$ & $\operatorname{Ti}(4)$ & $101.85(9)$ \\
\hline $\operatorname{Ti}(2)$ & $\mathrm{O}(1)$ & $\operatorname{Ti}(3)$ & $101.26(10)$ \\
\hline $\operatorname{Ti}(3)$ & $\mathrm{O}(1)$ & $\operatorname{Ti}(4)$ & $104.18(10)$ \\
\hline \multicolumn{4}{|c|}{$\mathbf{T i}-\left(\mu_{2}-\mathbf{O}\right)-\mathbf{T i}$} \\
\hline $\operatorname{Ti}(3)$ & $\mathrm{O}(29)$ & $\operatorname{Ti}(5)$ & $170.70(14)$ \\
\hline $\operatorname{Ti}(6)$ & $\mathrm{O}(30)$ & $\mathrm{Ti}(1)$ & $177.46(14)$ \\
\hline $\operatorname{Ti}(7)$ & $\mathrm{O}(31)$ & $\operatorname{Ti}(2)$ & $170.82(15)$ \\
\hline \multicolumn{4}{|l|}{ O-S-O } \\
\hline $\mathrm{O}(2)$ & $\mathrm{S}(1)$ & $\mathrm{O}(3)$ & $108.20(14)$ \\
\hline $\mathrm{O}(3)$ & $\mathrm{S}(1)$ & $\mathrm{O}(4)$ & $107.92(14)$ \\
\hline $\mathrm{O}(3)$ & $\mathrm{S}(1)$ & $\mathrm{O}(5)$ & 111.71(15) \\
\hline $\mathrm{O}(4)$ & $\mathrm{S}(1)$ & $\mathrm{O}(5)$ & $110.38(15)$ \\
\hline $\mathrm{O}(2)$ & $\mathrm{S}(1)$ & $\mathrm{O}(4)$ & $108.84(13)$ \\
\hline $\mathrm{O}(2)$ & $\mathrm{S}(1)$ & $\mathrm{O}(5)$ & $109.70(14)$ \\
\hline $\mathrm{O}(16)$ & $\mathrm{S}(2)$ & $\mathrm{O}(17)$ & $107.58(1$ \\
\hline $\mathrm{O}(16)$ & $S(2)$ & $\mathrm{O}(18)$ & 108.25(1'. \\
\hline $\mathrm{O}(16)$ & $\mathrm{S}(2)$ & $\mathrm{O}(19)$ & 110.41(1: \\
\hline $\mathrm{O}(17)$ & $S(2)$ & $\mathrm{O}(18)$ & $108.30(1<$ \\
\hline $\mathrm{O}(17)$ & $\mathrm{S}(2)$ & $\mathrm{O}(19)$ & 111.81(1: \\
\hline $\mathrm{O}(18)$ & $\mathrm{S}(2)$ & $\mathrm{O}(19)$ & $110.36(1$ \\
\hline${ }^{a}$ Footnote text. & & & \\
\hline
\end{tabular}

Table IV. IR Band positions and assignments for $\mathrm{Ti}_{8}$ cluster, $1600-500 \mathrm{~cm}^{-1}$.

\begin{tabular}{|c|c|c|}
\hline Band position $\left(\mathrm{cm}^{-1}\right)$ & Intensity & Assignment \\
\hline 520 & W & Ti-O str, Ti-OEt \\
\hline 550 & W & Ti-O str, Ti-OEt \\
\hline 608 & V str & Ti-O str, Ti-OEt \\
\hline 637 & $\mathrm{Sh}$ & Ti-O str, Ti-OEt \\
\hline 795 & str, unres & Ti-O-Ti str, $\mu_{2} \mathrm{O}$ \\
\hline 805 & str, unres & Ti-O-Ti str, $\mu_{2} \mathrm{O}$ \\
\hline 896 & M & C-C str, OEt (bridging) \\
\hline 928 & M & C-C str, OEt (terminal) \\
\hline 979 & M & C-O str, OEt (terminal) \\
\hline 1007 & M & $\begin{array}{l}\mathrm{C}-\mathrm{O} \text { str, OEt } \\
\text { (terminal+bridging) }\end{array}$ \\
\hline 1040 & str & C-O str, OEt (bridging) \\
\hline 1073 & M & C-O str, OEt (terminal) \\
\hline 1091 & $\mathrm{Sh}$ & $\mathrm{CH}_{3}$ rock, $\mathrm{OEt}$ \\
\hline 1126 & V str & $\mathrm{CH}_{3}$ rock, $\mathrm{OEt}$ \\
\hline 1160 & Sh & $\mathrm{CH}_{3}$ rock, $\mathrm{OEt}$ \\
\hline 1254 & W & S-O str, sulfate \\
\hline 1288 & M & S-O str, sulfate \\
\hline 1356 & W & \\
\hline 1379 & M & $\mathrm{CH}_{3}$ bend, $\mathrm{OEt}$ \\
\hline 1442 & W & $\mathrm{CH}_{2}$ wag, $\mathrm{OEt}$ \\
\hline 1471 & W & $\mathrm{CH}_{3}$ bend, $\mathrm{OEt}$ \\
\hline 1480 & W & $\mathrm{CH}_{2}$ bend, $\mathrm{OEt}$ \\
\hline
\end{tabular}

